\title{
Trafegando na Contramão com o Professor Calmon de Passos: Acesso à Justiça Versus Acesso ao Judiciário
}

\author{
Travel in the Opposite Direction with Professor Calmon De Passos: Access to Justice Versus \\ Access to the Judiciary
}

\author{
Cláudia Albagli Nogueira Serpa' \\ ${ }^{1}$ Universidade Federal da Bahia - UFBA, Brasil
}

\section{Resumo}

Trata-se de abordagem que analisa e reflete sobre acesso ao judiciário e acesso à justiça a partir da obra Revisitando o direito, o poder, a justiça e o processo, do Professor Calmon de Passos. No tema do acesso ao Judiciário, reflexões do professor sobre a linguagem jurídica, ativismo judicial e educação política. No campo do acesso à justiça, aspectos como a relação entre sentido de justo e as demandas humanas, a democracia como indispensável para a realização da justiça e a necessidade de recuperação de mediadores sociais de conflitos. Conclui-se apresentando propostas para melhoria do acesso ao Judiciário e alcance do sentido de justiça sob o olhar de Calmon de Passos.

Palavras-chave: Acesso à justiça; Acesso ao judiciário; Ativismo judicial

\begin{abstract}
It is an approach that analyzes and reflects on access to the judiciary and access to justice based on the work Revisiting the law, power, justice and the process of Professor Calmon de Passos. On the theme of access to the Judiciary, reflections by the professor on legal language, judicial activism and political education. In the field of access to justice, aspects such as the relationship between a sense of fairness and human demands, democracy as indispensable for the realization of justice and the need to recover social conflict mediators. It concludes by presenting proposals to improve access to the Judiciary and achieve a sense of justice under the eyes of Calmon de Passos.
\end{abstract}

Keywords: Access to justice; Access to the judiciary; Judicial activism

\section{Introdução}

O título aqui escolhido vem do subtítulo do livro Revisitando o direito, a justiça, o poder e o processo e é uma feliz síntese do que o professor Calmon de Passos nos permite nessa obra: trafegar na contramão dos lugares comuns da dogmática, das respostas simples da observação superficial do direito, da crença ilusória do funcionamento do Judiciário e do alcance da justiça. São escritos produzidos pelo Professor Calmon de Passos nos últimos anos de sua vida, sendo uma publicação póstuma, feita por sua filha, Eridan Passos. Isto só acresce a importância das reflexões de um homem que, octogenário, mostrava-se absolutamente atual, atento às transformações e mudanças do direito e do mundo. De um processualista que dedica-se à filosofia, à sociologia, a hermenêutica e transcende as observações habituais sobre a teleologia do processo.

Já a continuação do título, por mim adicionado, serve para trazermos à baila um debate já bem conhecido para quem estuda o tema do acesso à justiça, sobre o abismo existente entre o alcançar a justiça e o acesso material ao judiciário, entre a utopia da concretização do justo e os labirintos do Poder 
Judiciário. Mas esse tema (e qualquer outro!) lido através da ótica do professor Calmon de Passos e da sua escrita instiga-nos a pensar a realização do direito, suas imbricações e seus permanentes desafios, sendo o texto absolutamente a-histórico e em consonância com os desafios da contemporaneidade; mais ainda quando pensamos o recente e avassalador processo de tomada das tecnologias no direito, as mudanças postas para profissionais e cidadãos, e o horizonte de desafios que se vislumbra, inclusive nesse momento de pandemia em que nos colocamos fora da ordem, ou, ainda, diante de uma nova ordem.

Complementaram essas reflexões três textos biográficos sobre o Professor J.J. Calmon de Passos que estão publicados no livro $\mathrm{O}$ nome das salas ${ }^{1}$. Nesses também temos encontros com o Professor e conhecemos uma vez mais do seu brilhantismo e dimensão humana, da sua capacidade de falar sobre temas de ontem, mas com palavras que a cada dia são mais atuais fazendo-os parecer temas de agora.

Para desdobrar esses elementos, haverá uma inversão do título, primeiro trazendo aspectos ligados ao acesso ao Judiciário, obstáculos e questões postas pelo homenageado; depois tratando sobre acesso à justiça, definições de justo e o diálogo com problemas típicos da sociedade brasileira. Todo o texto construído em diálogo com o professor Calmon de Passos, de modo que boa parte do que vai nas próximas linhas são reflexões extraídas da obra do homenageado ${ }^{2}$ em cotejamento com problemas e reflexões do nosso tempo.

\section{Sobre judiciário e acesso ao judiciário}

No livro Revisitando o direito, o poder, a justiça e o processo, em diversos momentos o professor Calmon de Passos trabalha aspectos sobre o Poder Judiciário, quase sempre num tom crítico ao que ele considera um processo de endeusamento ou, para usar a precisão das suas palavras, "nosso atavismo de senhor do engenho investido de autoridade" (CALMON-DE-PASSOS, 2012, p. 208). Assim, coincidem na fala do autor várias questões que são apontadas como obstáculo para acesso ao Judiciário, no que se destaca para comentar dois deles: aspectos da cultura jurídica e aspectos educacionais que alcançam a sociedade.

No tema da cultura jurídica, parece-nos imprescindível trazer a visão do professor Calmon de Passos quanto a ser o direito linguagem, ser o direito um dizer travestido de coercitividade, um prescrever para cuja efetividade se está legitimado a utilizar a força (Ibidem, p. 53). A sua percepção em relação ao discurso jurídico é a de um discurso tecnocrata, que se constitui num obstáculo à emancipação dos indivíduos, elemento que considera imprescindível para o avanço dos indivíduos e das sociedades.

A crítica feita, portanto, não se cinge ao conteúdo dos discursos encampados por membros do Judiciário, mas à sua teleologia, que seria alcançar o sujeito comum, dizer-lhe o direito e, assim, emancipá-lo. Em sua visão, isso absolutamente não ocorre, muito pelo contrário, daí sua crítica. Fala de algo que já conhecemos bastante: sobre a inacessibilidade do discurso jurídico para a maioria daqueles a que se destina. Sendo o direito linguagem e sendo uma linguagem que não se compreende, não cumpre ele sua função ou, para Calmon de Passos, cumpre uma função desviante que é dissimular a dominação a que serve (Ibidem, p. 54).

Calmon falo-nos da linguagem jurídica como algo que deve estar conectada à construção do sujeito de direito, à elaboração da esfera pública e à possibilidade de efetivação dos direito pleiteados no Judiciário ou fora dele. Na ideia de esfera pública, enquanto arena de participação dos sujeitos políticos, conta a linguagem como o principal mecanismo de emancipação elaborando aquilo que Jürgen Habermas (HABERMAS, 2012) vai chamar de ação comunicativa e que, igualmente, inspira algumas leituras e divagações do nosso homenageado.

1 DIDIER Jr. Fredie (coord.) O nome das salas. Homenagem aos 125 anos da Faculdade Livre de Direito da Bahia. Salvador: Jus Podium, 2016.

2 Os elementos que pautaram a redação deste artigo foram retirados majoritariamente da seguinte obra do Professor Calmon de Passos: "Revisitando o direito, o poder, a justiça e o processo: reflexões de um jurista que trafega na contramão" (2012), livro que serviu de tema de debate para a mesa que participamos no Congresso Centenário de Calmon de Passos, ocorrido entre 09 e 11 de julho de 2020. 
Nessa mesma linha do direito como linguagem, o professor Calmon de Passos apresenta, já no início dos anos 2000, uma forte crítica ao comportamento ativista dos membros do Poder Judiciário, chamando a atenção para a imprescindibilidade da fundamentação que decide e justifica, ou seja, para a necessidade de uma fundamentação que esteja comprometida com apontar os reais elementos que conduziram o julgador a formar a sua convicção e emitir a decisão. Trata ainda da questão do compromisso do juiz com a veracidade e a coerência (Ibidem, p. 62). Neste ponto, explica (Ibidem, p. $62)$ :

Veracidade entendida como a exata correspondência entre o objetivo real da vontade expressa na conclusão e sua motivação subjetiva, o que reclama a coerência objetiva da fundamentação, isto é, sua fidelidade aos fatos, que devem corresponder a quanto comprovado, e sua coerência axiológica, que é a exata correspondência entre os valores em que se embasou a conclusão e os acolhidos pelo sistema positivado, a par de sua coerência subjetiva, que impõe um comportamento técnico-jurídico não-contraditório.

O autor está falando também de legitimidade da decisão, da importância de alcance do consenso e da necessidade do compromisso inexcedível por parte dos membros do Judiciário em estarem atentos aos elementos de veracidade das motivações da decisão. Observando que não se trata de verdade como conceito oposto de mentira, mas verdade como algo comprometido com os elementos constantes do processo (provas, alegações de ambas as partes, etc) e que preserva a racionalidade da decisão.

Calmon de Passos já antecipava àquela altura o que se torna uma das principais questões da teoria do direito, da hermenêutica jurídica e da filosofia do direito, qual seja: pensar os limites da atuação do Judiciário e o exercício do seu poder-dever. Aliás, essa é uma dimensão destacada pelo Mestre e que parece perdida na compreensão de uma parte significativa dos membros do Judiciário, vide a forte reação à recente Lei de Abuso de Autoridade aprovada pelo legislativo nacional em 2019, ou, ainda, pela resistente manutenção de privilégios da carreira que há muito precisam ser repensados. Por todos, como exemplo, a previsão de 60 (sessenta) dias de férias para os magistrados e membros do Ministério Público (art. 66, LC 35/79 e art. 51, Lei 8.625/93).

Calmon de Passos se coloca como forte crítico desses privilégios e do impacto disso no funcionamento do Judiciário, no olhar que se constitui na sociedade sobre os membros do poder e do quanto contribui para a sensação de encastelamento de um Poder que lida rotineiramente com a vida de indivíduos de todas as camadas sociais.

Por fim, ainda na dimensão do direito como linguagem, faz Calmon de Passos uma clara defesa da dimensão procedimental como garantia inexcedível do cidadão. Remetendo ao pensamento habermasiano, chama a atenção para a relevância do procedimento, menos pela forma, mais pela dimensão de garantia vinculada ao substancial jurídico, político e econômico associado ao processo.

O procedimento é elemento normativo a balizar a liberdade discursiva e assegurar a possibilidade de converter o argumento em fundamento racional da decisão jurídica. Resguarda em uma linha temporal, social e material, o quadro institucional para o desdobramento discursivo. O procedimento de que se fala é o procedimento valorativo, posto que oferece liberdade discursiva aos sujeitos processuais, mas impõe a eles poderes, faculdades e deveres, coordenando suas atividades, tudo com vistas a que seja atingida a finalidade última do processo, que é ofertar decisão socialmente legitimada.

Além disso, o espaço procedimental é um dos elementos a possibilitar a concretização do princípio democrático porque torna possível o exercício da autonomia política dos cidadãos. O exercício do discurso é que materializa a autonomia política do cidadão e transforma a ordem jurídica em consequência dos processos discursivos da vontade política dos sujeitos falantes. O autor do direito e seu destinatário passam a estar identificados num só sujeito através do discurso que colabora na formação da decisão jurídica. O procedimento é espaço e limite indispensáveis à racionalização dessa forma de democracia constituída na tessitura do discurso. A condição procedimental é que garante encontrar para o discurso condições de igualdade dos sujeitos para exposição de suas razões e colaboração no alcance do consenso. 
Portanto, o professor Calmon de Passos trata da questão da exigência de fundamentação conjuntamente com a questão do procedimento como garantia, entendendo este como mecanismo de controle e baliza do poder judicante (CALMON-DE-PASSOS, 2012, p. 62).

Já no campo da educação, mais uma vez o Professor é contundente ao apontar a ausência de formação política da população brasileira e de não ver espaço para a transformação cidadã. Trata da relação entre direito e política como co-originária, onde o direito é resultado de um ato de poder, assim como não há poder sem a garantia do direito. Por isso, vê a educação política como essencial para que o direito cumpra as suas funções para além do sistema de poder, como efetivo mecanismo de emancipação.

Calmon de Passos, em mais de uma passagem da obra, refere-se ao fato de haver no Brasil uma questão de fundo decorrente da ausência de preparo e formação para participação, luta e organização política, considerando esse caminho essencial para que se alterem as bases e as relações de poder (Ibidem, p. 79). A cultura democrática brasileira revela um povo pouco habituado a práticas cidadãs, com facilidade para a confusão entre o público e o privado, refletindo-se tais elementos nas instituições públicas que daí emergem.

Afirma que o político precede o jurídico (Ibidem, p. 59) - assim o faz obviamente sem se referir à política partidária, mas sim ao sentido essencial da política - e que os conflitos, antes de se constituírem em uma demanda do direito, são demandas da vida em sociedade, do sujeito como pessoa e cidadão de um estado, sendo a educação política essencial para que o sujeito alcance a sua real emancipação.

Também nessa passagem sobre a questão educacional, reconhece as mudanças perpetradas pela passagem democrática, pela existência da Constituição de 1988 e pelo entendimento do processo como espaço de reconhecimento do outro, convertendo-se numa meta institucionalizada, através das possibilidades de abertura progressiva à participação social. Quanto maior o espaço retórico, maior a possibilidade de se falar em Estado democrático constitucional, já que a decisão deixa de ser apenas fruto da autoridade do Estado, ganhando legitimidade pelo espaço colaborativo da sociedade, pela participação ativa dos sujeitos políticos, deixando estes a condição de meros destinatários das decisões.

Em outro momento, abordando a questão da tecnologia e do processo de substituição do homem nos espaços laborais, faz uma análise histórica do capitalismo, da industrialização e prospecta as possíveis consequências disso para a sociedade (Ibidem, p. 63). Neste e em outros momentos, sua obra impressiona pela atualidade da fala, pela capacidade de abordar questões em que se antecipa a fatos e a possibilitar reflexões que se renovam a cada leitura. Embora não tenha alcançado alguns dilemas que vivenciamos na contemporaneidade, seu pensamento é perfeitamente aplicável justamente porque enxerga além do óbvio.

Perguntamo-nos o que estaria o professor Calmon de Passos dizendo agora, quando a inteligência humana voltada para o direito é rapidamente substituída pelas inteligências artificiais, em que há a transposição das relações profissionais para mediadores tecnológicos e o quase apagamento da dimensão humana? Certamente identificaria esse processo como resultado do curso dos fatos, mas também estaria bradando quanto ao perigo de se eclipsar o papel do operador do direito.

As lições de Calmon continuam a ser absolutamente indispensáveis diante desse cenário atual, porque o Mestre antecipou-se em destacar os caminhos tortuosos do direito e as suas consequências como obstáculo para acesso ao Poder Judiciário, mormente para os cidadãos mais necessitados.

\section{Acesso à justiça}

O tema da justiça igualmente aparece na obra de Calmon com a clareza e o dom poético que tem. Exatamente isso: conduz-nos a refletir sobre o ser justo através de palavras fortes e trechos de poesia, assim como quem une coisas aparentemente óbvias. Leitura obrigatória aos que estão em formação e àqueles que já há muito militam no direito e que, por vezes, se perdem na aridez do cotidiano jurídico.

Traz de pronto duas afirmações que per si bastariam: que a justiça é indissociável da condição humana e que a justiça tem a ver com a satisfação de necessidades e desejos. 
Em relação à primeira afirmação, sobre ser indissociável da condição humana, Calmon de Passos faz um rápido apanhado de teorias que tentaram explicar a justiça e diz que ainda carecemos de uma definição objetiva do justo, sendo esta sempre uma avaliação de alguém. Ressalta, contudo, que o homem, diante de alternativas de justiça possíveis, impõe-se uma avaliação e escolha e a definição do telos torna-se uma atitude ética. Para ele a ética é base da moral e da justiça.

Ao falar de direito e da dificuldade na sustentação da definição do justo, remete-nos a algo que é bastante discutido por autores contemporâneos (ATIENZA, 1999; ALEXY, 2010) que é a pretensão de correção do direito. Essa ideia de que diante da ausência de uma definição objetiva de justiça, necessário se faz a compreensão da pretensão de correção do direito, justamente para afastar a hipótese da norma extremamente injusta.

Robert Alexy (ALEXY, 2010, p.117) diz que a pretensão de correção é um objetivo do direito, quando justifica a intrínseca relação deste com a moral. A textura aberta do direito, termo cunhado por Hart (HART, 2009), deriva, entre outras razões, da linguagem própria do direito, da possibilidade de contradições normativas e da falta de normas. Nessas situações o juiz ganha amplitude para a definição de sua decisão e encontra na pretensão de correção, enquanto exigência do direito, um limite externo à margem de flexibilidade derivada do direito e a realização do justo.

Já na segunda afirmação, sobre ter a justiça a ver com a satisfação de necessidades e desejos, Calmon de Passos diz que, inversamente, injustiça e carência são quase irmãs siamesas e ressalta que aquele que não experimentou carências materiais não se sente jamais injustiçado. O professor Calmon de Passos, ao sustentar a dificuldade em objetivar o sentido de justo, usa o caminho do que se sabe que é injusto, afirmando ser aquilo que decorre da carência, da inexistência de condições materiais de sobrevivência, o que extrai dos indivíduos o essencial para a sua dignidade. É a partir da busca por dar fim a essas condicionantes que se vislumbra a própria busca pela justiça.

Uma vez mais está o professor Calmon de Passos falando de emancipação, de desigualdades e dos obstáculos encontrados na sociedade brasileira.

Só essas duas primeiras afirmações já são suficientes para nos colocar diante de muito que vivemos e vivenciamos em nossa sociedade, mormente neste momento de pandemia, em que mais ainda se evidenciam as desigualdades provocadas pelas carências e em que se tornam ululantes as injustiças sociais.

Mas Calmon de Passos vai adiante e associa a noção de justiça à de democracia. Destaca ser indispensável o direito democraticamente organizado e democraticamente assegurado e coloca o papel das instituições como essencial para tanto. Ensina-nos que as instituições, em razão da sua permanência, são essenciais ao funcionamento do estado democrático de direito porque são as regras e as executam independente de partidos ou de quem esteja a frente do estado. As instituições do estado são, por consequência, elemento essencial para falar-se em justiça e democracia.

Diz que as instituições apenas são reais na medida em que são realizadas por indivíduos, ou seja, o substrato humano é tão determinante para a existência das instituições, quanto para os resultados por elas produzidos, que retornam aos próprios sujeitos (CALMON-DE-PASSOS, 2001, p.06). São os indivíduos que dão realidade, existência e que representam as instituições.

No espaço de abertura discursiva, o cidadão, "aquele que é governado sem ser oprimido" (IBIDEM,p.07), retoma para si a possibilidade de influenciar diretamente nas decisões do Estado, colaborando com o Poder Judiciário através do exercício livre e consciente da formulação de argumentos. É no espaço institucional que se faz possível o desempenho desse papel social, qual seja: o papel político de cidadão.

Calmon de Passos trata também da questão da existência de um processo justo e o relaciona com a consideração política do processo e realização das suas garantias. Diz ele (Ibidem, p. 62):

Se alguma justiça, no sentido mais lato e imprestável possível, se pode falar em termos de processo, essa justiça em verdade seria esgotada com a consideração política do processo em termos de garantias para a consecução daqueles interesses ou valores já apontados. Justiça e validade se equivaleriam. Por conseguinte, a dimensão de 
justiça do processo se esgota nas tradicionais garantias do devido processo legal, que hoje poderíamos ampliar para entendê-las como garantias do devido processo constitucional de produção jurisdicional do direito.

Ainda no tema justiça e democracia, vaticina que não há ordem jurídica que não realize alguma justiça, assim como não há ordem jurídica capaz de realizar a justiça absoluta (Ibidem, p. 79).

Por fim, Calmon de Passos coloca da necessidade de se recuperar os mediadores sociais de conflito como uma forma de aproximação do que se imagina do justo. Diz isso a partir da constatação da sobrecarga do Poder Judiciário, de uma espécie de superjudicialização de demandas da vida, que revelam o esgotamento de esferas outras de solução de conflitos. Para ele, isso decorre, entre outras razões, pela perda de mediadores sociais de conflitos, pela inexistência de mecanismos que desafoguem as demandas de uma sociedade prenhe de problemas e questões sociais, sendo a consequência mais evidente disso a busca massiva da autoridade e da coercitividade do Estado.

A juridificação das relações sociais e a judicialização de sua aplicação sem a democratização da sociedade mascara um retrocesso assustador, diz o Professor (Ibidem, p. 63). Falta-nos uma cultura política que assegure à população consciência para participação nos processos discursivos de formação da vontade, e pela busca de alternativas mediadas de solução. A realidade brasileira, marcada pelo clientelismo e pelas violências políticas, não permite ainda falar numa tradição em relação à prática pública, sendo uma das consequências disso o sobrecarregamento do Judiciário.

$\mathrm{Na}$ introdução à obra, a professora Marilia Muricy dá o seu depoimento sobre J. J. Calmon de Passos e destaca a questão de se recuperar os mediadores sociais de conflito (Ibidem, p. 25). Diz a Professora que Calmon de Passos compreendia terem esses se perdido na hipertrofia das competências típicas das sociedades contemporâneas: mediadores cujo lugar não pode ser ocupado por meras inovações na estrutura organizacional do Estado. Assim, nem a existência de normas, nem de instituições avançadas seriam suficientes para a transformação se as práticas de poder e gerenciamento de riqueza social reproduzem os antigos modelos de dominação. A cidadania é o fator decisivo para a mudança e o alcance da justiça.

Conclui que o conflito social não é técnico jurídico; é político, ético, social, existencial, marcado pelo contingente da condição humana.

\section{Propostas}

Na obra aqui discutida estão as últimas reflexões que o professor Calmon de Passos produziu em vida. No conjunto dos elementos até aqui apresentados, ele não deixou de indicar aquilo que entendia que seriam saídas possíveis para a mudança que esperava ver no direito e no funcionamento do Poder Judiciário. Portanto, mais do que a crítica contundente e construtiva, são também apresentadas propostas e soluções.

Em primeiro lugar, fala da necessidade do direito brasileiro se livrar do que ele chama de "sua prolixa constitucionalização" (Ibidem, p. 209). Para Calmon de Passos, a constitucionalização do direito tornara-se um elemento a obstaculizar o resultado prático das demandas, sobrecarregando as respostas do Judiciário e tornando difícil gerir o rol de direito previstos na Lei Maior. Além disso, entendia que a Constituição tinha acabado por ser uma lei a serviço da organização judiciária, garantidora de privilégios excessivos. Considerava um desvirtuamento da norma constitucional esse seu uso.

Nesse ponto, vejamos que o Professor Calmon de Passos caminha diametralmente oposto àquilo que prevalece no direito brasileiro, ou seja, a defesa da constitucionalização dos mais diversos temas como garantia da sua proteção. Calmon compreende, nesse particular, que a constitucionalização é mais obstáculo do que propulsão às mudanças necessárias na sociedade e relaciona com o já comentado fenômeno da superjudicialização.

Em outro momento, apresenta como alternativa que se assegure apenas ao Supremo Tribunal Federal (STF) a responsabilidade pelo controle de constitucionalidade, eliminando o controle difuso 
possível de ser exercido em outros graus de jurisdição e resguardando a essência de sua função constitucional.

Calmon de Passos caminha no sentido da defesa de um STF que funcione como Tribunal Constitucional, já que menciona a necessidade de se eliminar do órgão máximo do Judiciário as funções que considera desvirtuantes por não serem essencialmente constitucionais. O papel do STF deveria, portanto, cingir-se às questões constitucionais.

Aponta, ainda, a necessidade da extinção do quinto constitucional, que é a previsão de representantes dos advogados e do Ministério Público nos tribunais. Assim sugere por compreender que a formação do quinto é fator a punir a independência da OAB e do Ministério Público, devendo, portanto, ser revisto.

Mais uma vez opinião polêmica, pois vai de encontro à ideia de formação plúrima dos Tribunais e de consectários lógicos que complementariam o entendimento da advocacia como função essencial à justiça. De certo o fato de Calmon de Passos não se furtar à apresentar alternativas para a descaracterização de questões mesmo quando sabia que estas iam de encontro à maioria dos seus pares

Igualmente, entende equivocada a relação hierarquizada entre juízes do primeiro grau e os membros dos Tribunais. Entende que a diferença entre ambos está nas competências e que a saída é institucionalizar uma primeira instância independente e responsabilizável social e politicamente. Com isso, também, rever uma série de questões recursais que estão atreladas à existência dessa relação hierárquica, como o caso do agravo de instrumento, por exemplo.

Calmon de Passos não aprofunda nessa ideia, mas ao trazer este tema sugere uma alternativa que, ao mesmo tempo, reduziria a possibilidade de recursos, o tempo do processo e, ainda, imporia uma maior responsabilidade em relação às atividades dos juízes de primeiro grau, muitas vezes acobertados nos seus erros pelas possibilidade de apelo às instâncias superiores e correção de decisões judiciais. Vêse a opinião de quem experimentou diferentes posições na sua carreira jurídica e buscava contribuir com mudanças que entendia aprimorar a prestação jurisidicional.

Posiciona-se contrário à criação dos Conselhos Nacional de Justiça e Conselho Nacional do Ministério Público, ao que chama de "arremedo". Entende que o controle político dos membros do Judiciário deveria ser da sociedade, de modo a coibir os erros de julgamento e os comportamentos incompatíveis com a função jurisdicional. Nesse ponto o posicionamento do Professor Calmon coincide com a sua ideia de atribuir à sociedade responsabilidades e participação política, daquilo que em momento outro falamos aqui sobre sugerir os mediadores sociais de conflitos.

Inclusive, esse posicionamento continua em uma outra reflexão que faz, colocando a necessidade de destecnificação da solução de conflitos sociais e retirando da esfera do Poder Judiciário questões que em outros países já foram excluídas da sua apreciação. Como decorrência lógica, recuperar a capacidade social de autocomposição de conflitos.

Calmon de Passos coloca, ainda, a necessidade de eliminar o que ele denomina de "juízesenciclopédia", sendo aqueles que transitam do cível para o penal, do direito privado para o público, perdendo a capacidade real de conhecer e apreciar as demandas. A ideia é suprir uma possível deficiência dos julgadores, que, ainda que se esforcem, não pode alcançar a toda e qualquer matéria que lhe chegue para decidir. João Maurício Adeodato, analisando a extensão da atividade decisória, vai na mesma linha de Calmon de Passos, apontando que o magistrado tem que entender de tudo para decidir sobre tudo" (ADEODATO, 2002, p.217).

Também, a recomposição da carreira dos magistrados projetando melhorias em razão de tempo de serviço e de qualificação. Com isso, Calmon de Passos prevê a possibilidade de redução de custos, do redimensionamento das verbas salariais e da ampliação do número de magistrados para atender às reais necessidades do povo brasileiro. Vislumbrava uma outra proposto de carreira para magistratura com salários que deveriam ser pensados para estimular a progressão funcional, a formação contínua e a melhoria da prestação de serviço à população.

Por fim, aquilo que se constituía numa das mais contundentes críticas do Professor Calmon de Passos, o modelo dos Juizados Especiais, que ele definia como "uma arena gratuita para brigas de galo 
jurídicas” (Ibidem, p. 210). Entendia necessária a reformulação dos juizados para priorizar as conciliações e a participação de técnicos habilitados à composição dos litígios. Aqui, colocando em prática a sua proposta de recuperação de mediadores sociais através dos conciliadores leigos.

Mais uma vez Calmon antecipa-se a um debate absolutamente atual quanto a ampliação e valorização dos mecanismos alternativos de solução de litígios. O Professor tentava mostrar que de nada adiantava transferir aos juizados especiais os mesmos obstáculos e as mesmas questões próprias dos processos judiciais tradicionais. Mostra que é preciso criar formas de pôr fim aos conflitos judiciais sem a necessária participação dos juízes togados que seriam sempre insuficientes para o quantitativo de demandas que um modelo institucional como o dos Juizados Especiais favorece.

Destaque-se o fato de Calmon nos trazer essas reflexões quando os Juizados Especiais eram recebidos como a grande novidade e a grande solução para a celeridade tão esperada na prestação do serviço jurisdicional. Ainda no início dos anos 2000, momento em que dificilmente se levantava alguma voz contra a Lei 9.099/95.

Atualmente o que assistimos é uma corrida por parte daqueles que debatem e trabalham pela ampliação de acesso ao Judiciário. Conciliação e mediação são propósitos permanentes nas esferas processuais onde cabíveis e compõem muito do discurso que agora se estabelece em torno do aprimoramento dos serviços judiciais e da eterna busca do justo.

\section{Conclusão}

Para finalizar o diálogo com Calmon de Passos, que parece estar sempre mais atual, destacam-se duas passagens da obra analisada que entendemos sintetizar a ideia do jurista que trafega na contramão, que não se rende às ideias comuns e que se permite a atenção crítica.

Primeiro, a metáfora feita por ele a partir de um poema de Mario Quintana ${ }^{3}$ que fala de um viajante que chega a uma cidade e presencia os risos e alegrias de um circo que já foi embora. Calmon de Passos diz que é assim que nós do direito nos comportamos, como o viajante que fala de um circo que já se foi. Estamos sempre encampando discursos, ideias e bases teóricas de um mundo que já não existe mais.

Observando a realidade atual do direito, mais ainda parece real o que diz: vivenciamos um contexto de mudança brutal no direito com a tomada das tecnologias, a substituição das práticas humanas por inteligências artificiais e, enquanto isso, nós, profissionais do direito, ainda estamos discutindo se é bom ou ruim, se está certo ou errado ou como é que se faz. Falando das alegrias e risos de um circo que já passou.

É indispensável que despertemos para esse descompasso e coloquemos o direito pari passu ao mundo que existe e que também é nosso. Calmon não está mais entre nós, mas certamente observando a realidade atual, com o dedo em riste, bradaria a necessidade do direito adiantar-se frente às mudanças para não ser carregado pela correnteza.

A segunda passagem que destacamos diz respeito à energia e a clareza com que Calmon de Passos fala da indispensável relação entre direito e política. Mais do que isso, a força que coloca na formação e organização política como condição inexcedível para uma real mudança das bases e das relações de poder. O direito, na perspectiva do homenageado, era produto das classes dominantes e a ela servia, só havendo possibilidade de mudança desde quando houvesse pela sociedade uma tomada de consciência da política como algo que antecede e determina o direito. Afirma que o direito não emancipa; é um instrumento de estabilização do pacto de convivência entre dominante e dominado, sendo, pois, papel da formação política potencializar as condições de emancipação e, a partir disso, de transformação do direito.

Calmon sonhava com a emancipação humana e, para ele, não haveria emancipação sem a capacidade dos indivíduos de se situarem e atuarem politicamente. A lição do Mestre mostra-se cada dia 
mais vivaz e necessária, em um contexto onde "é preciso estar atento e forte" para garantir que os bons passos dados pelo direito não cedam às pressões e manobras típicas da nossa política. Viva Calmon de Passos, sua coragem e seus ensinamentos!

\section{Referências}

ADEODATO, João Maurício. Ética e retórica: para uma teoria da dogmática jurídica. São Paulo: Saraiva, 2002.

ALEXY, Robert. Direito e moral. Tradução de Paulo Gilberto Cogo Leivas. In: HECK, Luís Afonso (Org.). Direito natural, direito positivo, direito discursivo. Porto Alegre: Livraria do Advogado, 2010, p. 115-122.

ATIENZA, Manuel. Entrevista a Aleksander Peczenick. Doxa: Cuadernos de Filosofia del Derecho, n. 22, 1999, p. 660-670. Disponível em: <http://rua.ua.es/dspace/ bitstream/10045/10321/1/ doxa22_29.pdf>. Acesso em: 13 abr. 2020.

BAHIA, Saulo José Casali. “José Joaquim Calmon de Passos”. In: DIDIER JR, Fredie. Os nomes das salas: homenagem aos 125 anos da Faculdade Livre de Direito da Bahia. Salvador: Juspodivm, 2016.

CALMON-DE-PASSOS, J. J.. Revisitando o direito, o poder, a justiça e o processo: reflexões de um jurista que trafega na contramão. Salvador: Juspodivm, 2012.

Cidadania tutelada. Revista Diálogo Jurídico, ano 1, v. 1, n.7, outubro de 2001. Disponível em: <http://www.direitopublico.com.br/pdf_7/ DIALOGOJURIDICO-07-OUTUBRO-2001-CALMON-PASSOS.pdf>. Acesso em: 2 jul. 2020.

DIDIER JR., Fredie. “José Joaquim Calmon de Passos”. In: DIDIER JR, Fredie. Os nomes das salas: homenagem aos 125 anos da Faculdade Livre de Direito da Bahia. Salvador: Juspodivm, 2016.

GÓES E GÓES, Maurício Dantas. “O maior mestre que tive”. In: DIDIER JR, Fredie. Os nomes das salas: homenagem aos 125 anos da Faculdade Livre de Direito da Bahia. Salvador: Juspodivm, 2016.

HABERMAS, Jürgen. Teoria do agir comunicativo: racionalidade da ação e racionalidade social. Tradução de Flávio Siebeneichler. São Paulo: Martins Fontes, 2012, vol. II.

HART, Herbert Lionel Adolphus. O conceito de direito. Tradução de Antônio de Oliveira SetteCâmara. São Paulo: Martins Fontes, 2009.

OLIVEIRA, Manfredo Araújo. Moral, direito e democracia: o debate Apel versus Habermas no contexto de uma concepção procedimental da filosofia prática. In: MOREIRA, Luiz. (Org.). Com Habermas, contra Habermas: direito, discurso e democracia. São Paulo: Landy, 2004, p. 145176.

MURICY, Marília. Senso comum e direito. São Paulo: Atlas, 2015. 